\title{
Intervenção com a família pra o fortalecimento dos vínculos familiares no enfrentamento da violência contra a criança e o adolescente
}

\author{
Family intervention for the strengthening of family bonds in facing the violence against \\ the children and adolescent
}

\author{
Dione Lolis* \\ Lisa Mitiko Koga Kuriki**
}

\begin{abstract}
Resumo:
Este estudo foi desenvolvido em uma comunidade de alta vulnerabilidade social e que convive com diversas situações de violência. Situações essas que motivaram esta pesquisa, que tem por objetivo discutir sobre a importância da intervenção com a família para o fortalecimento dos vínculos familiares no enfrentamento da violência contra a criança e o adolescente. É uma pesquisa qualitativa, realizada no âmbito do trabalho de uma das equipes do Programa Atitude de Londrina, da Secretaria de Estado da Criança e Juventude do Paraná, na qual foram utilizados os registros das visitas institucionais, os relatórios da equipe de trabalho, os registros de campo do grupo com famílias e ainda uma discussão grupal direcionada por um roteiro de questões semiestruturadas. Constata que as relações de violência nas famílias decorrem de sua vivência, da aprendizagem e de sua realidade de extrema vulnerabilidade social. Verifica que o trabalho da equipe possibilitou que as famílias refletissem sobre suas próprias vivências e, por outro ângulo, permitiu que dessem os primeiros passos para a mudança, podendo colaborar no enfrentamento das violências. Não pretende aqui concluir nenhuma ideia, mas compartilhar experiências significativas, esperando que possa fomentar outras discussões, reflexões e novas propostas de trabalho nessa área.
\end{abstract}

Palavras-chaves: Família. Criança e adolescente. Violência. Fortalecimento de vínculos. Trabalho com famílias.

\begin{abstract}
:
This study was developed in a community of high social vulnerability that coexists with several kinds of violence. The situations, that motivated this research, have the purpose to discuss the importance of intervention in the family to strengthening its ties in order to face the violence against children and adolescents. It's a qualitative
\end{abstract}

\footnotetext{
* Possui graduação em Serviço Social pela Universidade Estadual de Londrina (1985), mestrado em Serviço Social pela Pontifícia Universidade Católica de São Paulo (2001) e doutorado em Sociologia pela Universidade Estadual Paulista Júlio de Mesquita Filho (Campus de Araraquara) (2008. dionelolis@uel.br

** Psicóloga, formada pelo Centro Universitário Filadélfia. Especialista em Desenvolvimento Gerencial e Consultoria pela Faculdade Estadual de Ciências Econômica de Apucarana/Instituto Brasileiro de Estudos e Pesquisas Socioeconômicos; em Psicologia Organizacional e do Trabalho pela Universidade Estadual de Londrina; e em Gestão de Políticas Públicas para a Criança e Juventude pela Universidade Estadual de Londrina. lisa_koga@hotmail.com
} 
survey, conducted with work objective of one of teams of the Londrina Attitude Program, of a Government program idealized by the State Department of children and Youth of Paraná, in which were used the records of institutional visits, the reports from the staff, the group field records with the families, and even a group discussion guided by a script with semi structured issues. The present work also notes that the relations of violence in families stem from their experience, their learning progress and social reality of extreme vulnerability. According the research, it also could be seen that the team's work made it possible for the families to reflect on their own experiences and, further, allowed they could take the first steps for change and collaborate in addressing the violence. It is not the purpose of this work end any idea here, but share important experiences that can foster further discussions, reflections and new proposals for work in this area.

Keywords: Family. Children and adolescents. Violence. Strengthening family ties. Working with families.

\section{Introdução}

Este estudo foi desenvolvido no decorrer da experiência de trabalho de uma das equipes do Programa Atitude de Londrina, sendo esse um programa de Governo idealizado pela Secretaria de Estado da Criança e Juventude do Paraná (SECJ), o qual foi discutido e aprovado pelo Conselho Estadual dos Direitos da Criança e do Adolescente (CEDCA). A implantação desse Programa ocorreu em março de 2009 e envolveu 10 municípios do Paraná sendo: Almirante Tamandaré, Cambé, Cascavel, Colombo, Foz do Iguaçu, Londrina, Piraquara, Ponta Grossa, Sarandi e São José dos Pinhais. As cidades foram elencadas a partir do levantamento de maior índice de violência praticada e sofrida por crianças e adolescentes.

O Programa tinha por finalidade alcançar os direitos e garantias assegurados no Estatuto da Criança e do Adolescente (ECA), que em seu artigo $4^{\circ}$ preconiza a prioridade absoluta da criança e do adolescente na efetivação dos seus direitos, e que ainda no inciso " $c$ " de seu parágrafo único, prevê que essa prioridade deve compreender a execução e a formulação de políticas públicas (BRASIL, 1990).

Cada Município teve as ações do Programa direcionadas aos territórios, considerando-se os fatores de risco social, alto índice de violência sofrida e praticada por crianças e adolescentes e a escassez de serviços e equipamentos públicos. A gestão teve, em seu formato, uma proposta de articulação e a integração entre Estado, Município e 
sociedade civil organizada, no que diz respeito ao repasse e uso de recursos, bem como no processo de construção e execução das ações.

Para direcionar as atuações da equipe técnica do Programa, foram definidos pela Secretaria de Estado da Criança e Juventude do Paraná (SECJ) os seguintes eixos de ação:

1. Fortalecimento dos vínculos familiares;

2. Superação da violência contra crianças e adolescentes e criação de Rede de Proteção;

3. Práticas formativas, socializadoras e de cidadania;

4. Abordagens educativas e terapêuticas ao usuário de drogas;

5. Fortalecimento das estruturas do Sistema de Garantia dos Direitos das Crianças e dos Adolescentes;

6. Participação Social da Juventude (PARANÁ, 2009, p. 23).

No Município de Londrina, o Programa Atitude foi aprovado pelo Conselho Municipal dos Direitos da Criança e do Adolescente (CMDCA) em 2008 e iniciado em março de 2009, com previsão de encerramento em dois anos. ${ }^{1}$ Foram envolvidas as diversas secretarias e instituições no trabalho, ficando a Secretaria Municipal de Assistência Social (SMAS) responsável pela gestão desse.

Para a execução das ações, além da equipe técnica, foram estabelecidos convênios com duas instituições para o trabalho com as famílias, duas instituições para ofertar cursos profissionalizantes aos adolescentes, e uma para o tratamento de dependentes do uso de drogas. A Secretaria de Cultura e a Fundação de Esportes responsabilizaram-se pelo suporte às oficinas culturais e esportivas, respectivamente.

O local de atuação da equipe para a execução das ações foi em espaços públicos e comunitários como praças, ruas, campos, escolas, associação de moradores, igrejas, entre outros, de acordo com as suas condições e a disponibilidade.

Os núcleos do Programa Atitude em Londrina estavam localizados em cinco regiões, a saber: Sul/Rural, Oeste A, Oeste B, Leste e Centro/Norte. Cada núcleo foi composto por uma equipe interdisciplinar de cinco técnicos sendo: dois psicólogos, um assistente social, um educador artístico e um educador físico, além de dois cientistas sociais que acompanhavam o trabalho de todos os núcleos. Uma dessas equipes, da qual fizemos parte,

\footnotetext{
${ }^{1}$ Em março de 2011 foi firmado um novo convênio entre os governos estadual e municipal ficando esse último responsável pelo Programa Atitude e em dar continuidade às atividades.
} 
desenvolveu o trabalho na região Centro-Norte, que abrange três bairros: Quati, o Paraíso e o Paulista.

A prática profissional no cotidiano, no qual as crianças e adolescentes estavam inseridas e as relações estabelecidas no âmbito do Programa Atitude de Londrina nos fizeram presenciar muitas situações de violência, principalmente nas relações familiares. No entanto, os responsáveis e a comunidade como um todo pareciam considerar essas atitudes como forma de disciplinar, de educar.

O Estatuto da Criança e do Adolescente (ECA) (BRASIL, 1990, p. 4), em seu artigo 4", atribui à família, por ser a primeira instituição social, a responsabilidade para a "efetivação dos direitos referentes à vida, à saúde, à alimentação, à educação, ao respeito, à liberdade". Entretanto, o Estatuto corresponsabiliza a comunidade, a sociedade em geral e o Poder Público na efetivação desses direitos citados.

Dessa forma, em se tratando de uma prática no âmbito de um Programa de Governo na qual tem, dentre seus eixos prioritários de ação, o fortalecimento dos vínculos familiares, a superação da violência contra crianças e adolescentes e a criação de redes de proteção, tornava-se primordial a atuação junto à família.

Um olhar descuidado e apressado dessa realidade poderia levar a avaliações estigmatizantes e preconceituosas, interferindo na nossa prática diária. Foi preciso compreender como as pessoas interagiam nas relações sociais estabelecidas na família e na comunidade em que elas viviam, conhecendo e analisando as características ali presentes para que pudéssemos favorecer mudanças que permitiriam o enfrentamento de tais situações e a redução da violência contra crianças e adolescentes.

A autora Lydia Onesti (2003, p. 3) enfatiza em seus estudos que situações adversas como as condições precárias de sobrevivência, a situação de pobreza, somado aos aspectos como doenças, inseguranças de moradia, privações, "vizinhança perigosa" e envolvimento em atos ilícitos atuam como agentes estressantes e contribuem para a formação de vulnerabilidades, tanto orgânicas como psicológicas. Tais condições não são os únicos determinantes para o comprometimento da qualidade de vida pessoal, a este quadro são somados aos sucessivos fracassos nas tentativas de enfrentamento das condições vividas no cotidiano. 
Com esse entendimento e, considerando a família como primeiro grupo responsável pela tarefa socializadora, a principal influência norteadora do desenvolvimento da personalidade da criança e do adolescente, este estudo pretendeu discutir sobre a importância da intervenção com a família para o fortalecimento dos vínculos familiares no enfrentamento da violência contra a criança e o adolescente. Para tanto, seus objetivos abarcavam conhecer os significados da violência; discorrer sobre o processo de intervenção com as famílias; identificar as reflexões geradas nos encontros com o grupo e verificar se essas possibilitariam mudança de atitude no enfrentamento da violência intrafamiliar, bem como contribuir com a reflexão sobre o trabalho com famílias.

Para o trabalho aqui proposto, foram utilizados os registros das visitas institucionais realizadas pela equipe nos bairros de abrangência do Núcleo Centro/Norte, as quais foram realizadas entre a primeira quinzena de março e a segunda quinzena de abril de 2009 , os relatórios da equipe de trabalho e os registros de campo feitos durante as discussões dos encontros realizados com o grupo com famílias, no período de junho a dezembro de 2010. Realizou-se, ainda, uma discussão direcionada por um roteiro de questões com o mesmo grupo de famílias. Deve-se considerar que este trabalho em grupo se formou após um ano de atividades no bairro Quati.

Foram realizados 7 encontros com esse grupo, para os quais foram convidadas 17 famílias de crianças e adolescentes do bairro Quati de Londrina, participantes do Programa. Destas 17 famílias, 11 foram representadas por mulheres, as quais participaram em mais de 4 encontros, 4 em pelo menos 1 encontro e apenas 2 não compareceram em nenhum encontro.

Para a discussão grupal, foi elaborado um roteiro prévio, com questões semiestruturadas, as quais abordavam a compreensão sobre a violência, a contribuição do trabalho em grupo nas relações familiares e o seu formato e sobre o trabalho desenvolvido pela equipe no bairro. Essa discussão foi realizada em dezembro de 2010, e foi gravada mediante autorização prévia dos participantes mediante termo de consentimento livre e esclarecido. Para manter sigilo, foram criados nomes fictícios, sendo esses escolhidos pelas próprias participantes.

Para a coleta e a análise dos dados, optou-se pela abordagem qualitativa, uma vez que ela abrange uma realidade que não pode ser quantificada. Maria Cecília Minayo (2003) 
afirma que a pesquisa qualitativa aprofunda-se no mundo dos significados das ações e relações humanas e que tem, como um dos elementos centrais, a compreensão da realidade humana vivida socialmente.

Assim, adotamos o método qualitativo para avaliar o processo de intervenção com as famílias, uma realidade dinâmica, em constante mudança e em construção. Ainda que cientes da importância da pesquisa quantitativa, essa não foi considerada neste estudo.

Pretende-se, ainda, compartilhar uma experiência e contribuir na reflexão do trabalho com as famílias para o seu fortalecimento. Para tanto, abordaremos de forma breve sobre o tema violência, família e em seguida faremos uma descrição deste trabalho e as discussões sobre os dados colhidos na entrevista grupal.

\section{Violência e família}

Vivenciamos uma realidade na qual a discrepância entre os níveis econômicos e sociais, a fragmentação do coletivo e a exacerbação das violências é evidente no mundo como um todo. Presenciamos constantemente os impactos dessas violências sobre as relações familiares, na sua dinâmica, nas suas rotinas e nas práticas educativas.

Pesquisar essa dinâmica requer a leitura e a reflexão sobre a sociedade contemporânea, considerando todas as transformações éticas, culturais e sociais, bem como as científicas, políticas e tecnológicas, e sobre os desdobramentos dessas transformações na individualidade do sujeito e o impacto na coletividade. Somado a isso, é necessária uma compreensão conceitual da violência como uma construção histórica e social da qual as famílias fazem parte.

Minayo e Souza (1999, p. 10), no escrito exposto, explicitam a importância de tal compreensão: “É muito difícil conceituar a violência, principalmente por ser ela, por vezes, uma forma própria de relação pessoal, política, social e cultural; por vezes uma resultante das interações sociais; por vezes ainda, um componente cultural naturalizado".

Nos estudos sobre esse termo, os pesquisadores afirmam que ele é muito complexo. Minayo e Souza (1999) fazem um breve levantamento histórico sobre os estudos da violência, afirmando que os grandes pesquisadores the conferem um caráter de ambiguidade, ora sendo considerada como fenômeno positivo, ora como negativo. 
Dessa forma, evidencia-se a complexidade desse fenômeno social que é a violência e que se apresenta em diferentes configurações, sofrendo influências históricas e conjunturais.

Yves Michaud (2001, p. 7), em seus estudos sobre violência, recorreu aos dicionários franceses contemporâneos deparando-se, pois, com as seguintes definições:

[...] a) o fato de agir sobre alguém ou de fazê-lo agir contra a sua vontade empregando a força e a intimidação; b) o ato através do qual se exerce a violência; c) uma disposição natural para a expressão brutal dos sentimentos; d) a força irresistível de uma coisa; e) o caráter brutal de uma ação.

Para o autor, a partir desses variados sentidos, tornam-se evidentes duas orientações principais: de um lado, os fatos e as ações que se opõem a paz, a ordem, e de outro, a maneira de ser da força, do sentimento que se opõe a força brutal que desrespeita as regras. Michaud $(2001$, p. 8) retoma ainda a origem da palavra violência a qual:

[...] vem do latim violentia, que significa violência, caráter violento ou bravio, força. O verbo violare significa tratar com violência, profanar, transgredir. Tais termos devem ser referidos a vis, que quer dizer força, vigor, potência, violência, emprego de força física, mas também quantidade, abundância, essência ou caráter essencial de uma coisa.

Fica evidente que a violência é algo intenso, de força que deixa marcas, no entanto, segundo o autor, essa força assume sua qualificação de violência em função das normas definidas por uma sociedade e que variam muito. Tal variação dificulta a definição desse termo e expande a uma diversidade de definições.

Yves Michaud (2001, p. 11), no intuito de fornecer uma definição que abarcasse tanto os estados quanto os atos de violência, constatou que há violência:

[...] numa situação de interação, um ou vários atores agem de maneira direta ou indireta, maciça ou esparsa, causando danos a uma ou várias pessoas em graus variáveis, seja em sua integridade física, seja em sua integridade moral, em suas posses ou em suas participações simbólicas e culturais.

A descrição do nosso cotidiano e os noticiários nas mídias revela o quanto essa violência predomina na nossa forma de interação, seja na interação entre as pessoas, entre as pessoas e as instituições sociais, entre as pessoas e a natureza, e isso acaba por banalizar a violência, fazendo com que não percebamos o seu papel em nossas formas de interação. 
Ana Luisa Sallas et al. (2008) afirma que é na inexistência e/ou precariedade das ações da esfera pública que a violência emerge, atingindo particularmente os mais pobres, as crianças e os adolescentes que vivem nas ruas e assim por diante.

Na concepção de Marisa Feffermann (2006), na atual sociedade brasileira, a violência permeia várias práticas, despojando as pessoas de seus direitos como indivíduo e como cidadão, causando transtornos físicos e psíquicos. Tais práticas tornam-se formas de manipulação cada vez que são desvendadas, ainda que parcialmente, por serem práticas de dominação.

A classificação mais usual em estudos que tratam da violência é: violência física, psicológica e sexual. Entretanto, nas análises de situações concretas, verificou-se que essas diferentes formas de violência não são mutuamente excludentes, mas cumulativas e geram comprometimento no desenvolvimento integral de crianças e adolescentes. Nesse sentido, fazemos uso da classificação de violência já existente, dividida em três grandes categorias, conforme a Organização Mundial da Saúde (apud PARANÁ, 2009, p. 7):

\footnotetext{
Violência autodirigida: que inclui dano físico causado a si próprio; esta categoria é subdivido em comportamento suicida e autoflagelo;

Violência interpessoal: que se relaciona com ferimentos ou danos causados por um indivíduo a outro, parente (violência doméstica) ou não (violência comunitária);

Violência coletiva: compreendida como atos danosos cometidos por um grupo; tais atos podem ter motivações políticas, econômicas ou sociais.
}

Neste estudo, centramo-nos na violência interpessoal, quando dirigida às crianças e aos adolescentes, face aos impactos profundos e decisivos para suas trajetórias de desenvolvimento.

É importante citar que uma pesquisa realizada com jovens de Curitiba, de autoria de Ana Luisa Sallas et al. (2008), revela o quanto o universo familiar desses jovens é permeado de "pequenas" e "grandes" violências em seu dia a dia, o que acaba banalizando os castigos físicos, maus-tratos, agressões verbais ou físicas como forma de solucionar os conflitos nas relações familiares, comunitárias e também em outros grupos de convivência.

Viviane Guerra (1998, p. 31), em congruência com a autora supracitada, analisou o quanto a violência doméstica está relacionada à violência estrutural, ou seja, entre diferentes classes sociais, mas "é um tipo de violência que permeia todas as classes sociais 
como violência de natureza interpessoal". No que diz respeito à violência contra crianças e adolescentes, Guerra afirma:

[...] representa todo ato ou omissão praticado pelos pais, parentes ou responsáveis contra criança e/ou adolescentes que - sendo capaz de causar dano físico, sexual e/ou psicológico a vítima - implica, de um lado, uma transgressão de poder/dever de proteção do adulto e, de outro, uma coisificação da infância, isto é, uma negação do direito que crianças e adolescentes tem de ser tratados como sujeitos e pessoas em condição peculiar de desenvolvimento (GUERRA, 1998, p. 32).

Ao resgatarmos as histórias familiares nas nossas experiências ouvimos que o castigo físico em crianças e adolescente era utilizado como recurso legal para disciplinar, educar, e isso tanto no contexto familiar quanto no contexto escolar. Em seus estudos, Ana Luisa Sallas et al. (2008) constataram que, somente os últimos trinta anos trouxeram transformações para essas práticas, momento em que as escolas e as famílias passaram a questionar e a serem questionadas sobre a aplicação dos castigos físicos.

Entretanto, Maria Zamberlan e Maura Freitas (2003) pontuaram, por outro lado, que pesquisas sobre essa temática evidenciam cada vez mais registros de violência intrafamiliar, como: abuso emocional, físico e sexual, além da negligência e do abandono. Assim, investigaram que tais violências são originárias das relações interpessoais assimétricas e hierárquicas, marcadas pela desigualdade e subordinação, podendo ser fruto de um conflito ou ser um padrão de relacionamento que acompanha a história familiar.

De acordo com Guilherme Schelb (2005), uma pesquisa realizada no Brasil com adolescentes autores de homicídios, estupros e roubos, revelou que $80 \%$ sofreram graves abusos físicos, sexuais e psicológicos na infância e na adolescência. $O$ autor afirma ainda que, independentemente de outras causas que influenciam para a criminalidade, é inegável que uma atuação preventiva na infância e na adolescência contribua para a redução dos níveis de violência.

Ao referirmos à infância, automaticamente, remetemo-nos ao contexto familiar, espaço esse, o qual, conforme Maria do Carmo Carvalho (2006), espera-se que seja lugar de cuidados, proteção, aprendizado dos afetos, construção de identidades e vínculos relacionais de pertencimento, capazes de promover melhor qualidade de vida de seus membros e efetivar inclusão social na comunidade e sociedade em que vivem. 
Atualmente, deparamo-nos com grupos familiares diversos na sua composição e, para estudar sobre esse tema, fez-se necessário ter claro a que família nos referimos. Assim, o conceito que melhor define as famílias com as quais trabalhamos refere-se a:

Um grupo de pessoas, vivendo numa estrutura hierarquizada, que convive com a proposta de uma ligação afetiva duradoura, incluindo uma relação de cuidado entre os adultos e deles para com as crianças e idosos que aparecem nesse contexto (GOMES apud SZYMANSKI, 2006, p. 26).

Nesse sentido, nos foi preciso olhar os diferentes arranjos familiares sem rotular as famílias como incapazes ou desagregadas, de modo a compreendê-las no seu contexto social.

Silvia Lane (apud ZAMBERLAM; FREITAS, 2003) afirma que a família constitui-se o núcleo, que tem por função desenvolver a socialização básica de seus membros e é possuidora de uma relativa autonomia, visto que se organiza a partir de regras oriundas de complexas interações entre diversas variáveis. Assim, surgem formas variadas e particulares de organização interna do grupo familiar, no que tangem aos aspectos econômicos, sociais e culturais que perpassam a sua dinâmica.

Para Danda Prado (apud ZAMBERLAM; FREITAS, 2003), as funções que cada família desempenha estão diretamente relacionadas à parte que cada uma delas ocupa na organização social e na economia da sociedade a qual pertence. Dessa forma, pontua que é fundamental que tenhamos em vista as expectativas sociais que existem em relação à família, pois só assim é possível compreender o processo e o contexto de socialização das crianças nelas inseridas.

Nesse sentido, Maria do Carmo Carvalho (2006) enfatiza a necessidade de um olhar a esse grupo no seu movimento, buscando enxergar na diversidade não só os pontos de fragilidade, mas a riqueza das respostas possíveis descobertas pelos grupos familiares, dentro de sua cultura, para as suas necessidades. Para tanto, a autora ressalta que, para o potencial protetor e relacional apontado por estas famílias, só é passível de otimização se ela própria receber atenções básicas.

\section{A realidade e o trabalho}


Este estudo foi realizado no bairro Quati, o qual se localiza, geograficamente, entre um fundo de vale, o Ribeirão Quati, e diversas empresas. Esse Ribeirão, conforme relatos de técnicos de referência da rede de serviços ${ }^{2}$ visitados, está infectado e transmite algumas doenças. Segundo dados da Companhia Habitacional de Londrina (COHAB-LD), a população estimada é de 117 habitantes, sendo 39 unidades habitacionais. A sua ocupação ocorreu em agosto de 1993, há cerca de 20 anos, e a situação de irregularidade permanece até os dias atuais. No entanto, de acordo com as informações obtidas em contato telefônico com a própria $\mathrm{COHAB}$, no período da pesquisa estavam recolhendo os documentos para outorgar a regularização dos terrenos (KURIKI et al., 2009).

A infraestrutura do bairro conta com duas ruas asfaltadas e com energia elétrica, sendo que parte da população não tem acesso a essa energia de forma regularizada. No início da ocupação, havia cerca de 46 famílias instaladas na região. Hoje, encontram-se por volta de 50, caracterizando certa permanência das famílias que ali residem (KURIKI et al., 2009).

Em se tratando de bairro já delimitado como área de alta vulnerabilidade social e com influência do tráfico de drogas, discutimos, inicialmente, em equipe qual seria a melhor estratégia para adentrarmos na comunidade. O primeiro passo foi buscar informações da realidade, com objetivo de fazer um diagnóstico. Para tanto, realizamos visitas aos serviços governamentais e não governamentais que atendem a essa comunidade, visando conhecer o olhar de cada um dos agentes institucionais em relação à dinâmica, às vulnerabilidades, às potencialidades e às ações já realizadas nesse bairro.

Nesse primeiro contato, a equipe observou que os serviços não conseguiram pontuar potencialidades da comunidade, aspecto esse que trouxe preocupação aos técnicos para que ficassem atentos a esse ponto ao adentrar no bairro. Por outro lado, identificou-se que as considerações dos agentes dos serviços que atendem a comunidade Quati era a mesma no que se refere a pouca estrutura, à falta de equipamentos sociais, ao alto índice do envolvimento com o tráfico de drogas, à degradação do meio ambiente, bem como, no que tange à dependência da população em relação aos serviços oferecidos in loco.

\footnotetext{
2 Unidade Básica de Saúde, Centro de Referência da Assistência Social, escolas estadual e municipal, Pastoral da criança e vicentinos da igreja católica.
} 
Os técnicos do serviço da Unidade Básica de Saúde (UBS) afirmaram que é uma comunidade que não busca os serviços localizados fora do bairro, apresentando dificuldade em seguir as orientações prestadas por eles, principalmente no que se refere a questões de saúde. Tais comportamentos se repetem em outros serviços, tendo como consequência uma desmotivação generalizada na proposta de outras atividades, acarretando uma visão dessa comunidade, por esses profissionais, enquanto "acomodada e descompromissada" (KURIKI et al., 2009).

Após essa primeira leitura, a estratégia da equipe foi solicitar que o redutor de danos 3 da UBS comunicasse aos adolescentes sobre o trabalho a ser desenvolvido pela equipe no bairro. Fomos recebidos pelas crianças que estavam nas ruas e os adolescentes foram aproximando-se aos poucos, talvez motivados pela curiosidade. Nessa primeira atividade, a que denominamos "rua de recreio", reuniram-se por volta de 30 crianças e adolescentes, os quais foram divididos em dois grupos para atividades de recreação. Dentre os adolescentes, somente as meninas participaram ativamente pontuando atividades de interesse e queixas pela ausência dessas. Os meninos, por sua vez, permaneceram apenas na observação das atividades.

A partir desse primeiro contato, refletimos e discutimos sobre as ações seguintes. Foram propostas atividades dentro das condições e possibilidades da equipe, dando prioridade àquelas levantadas pelas crianças e adolescentes. E assim, aos poucos, instalamos as oficinas de esportes, atividades lúdicas e, paralelamente, iniciamos o acompanhamento das famílias das crianças e adolescentes mediante visitas e atendimentos domiciliares.

A vivência semanal nessa comunidade permitiu-nos presenciar constantemente as relações de conflitos nas interações familiares, principalmente dos responsáveis para com os filhos, bem como entre as próprias crianças, o que dificultava em muito o desenvolvimento das atividades propostas pelos técnicos de educação física e de artes. Aos poucos, fomos percebendo que as crianças dificilmente conseguiam brincar sem se agredirem mutuamente, de forma verbal e/ou física.

\footnotetext{
${ }^{3}$ Profissional que trabalha com as práticas de redução de danos causados pelo uso abusivo de substâncias entorpecentes, que visa incentivar o dependente a cuidar de si.
} 
As ações na comunidade foram constantemente discutidas, avaliadas e repensadas para que não fossemos apenas mais um serviço de passagem na vida daquela população. As queixas iniciais da comunidade ecoavam em nossa prática diariamente. As adolescentes meninas, ao longo de um período, questionavam-nos se não iríamos desistir do trabalho com elas.

Nos primeiros seis meses de trabalho com a comunidade, passamos por vários momentos de oscilação na relação com os moradores, ora de confiabilidade, ora de descrença. Víamos que qualquer ação dos serviços que atuavam na comunidade de forma isolada, ou seja, sem se articular, refletia no nosso trabalho diretamente. Assim, surgiu mais uma prioridade: a articulação da rede de serviços de forma mais próxima. Além das discussões de caso e encaminhamentos a tais serviços, planejamos em conjunto as estratégias de intervenção. Uma delas foi a realização de uma atividade, a qual denominamos "dia da beleza". Nesse dia, foram oferecidos vários serviços como o de beleza, orientações de saúde, atividades de recreação e de artesanatos. Com esta ação, a comunidade pôde ter seu destaque na mídia de forma positiva.

A partir das constantes avaliações das intervenções, após um ano de trabalho, constatamos a necessidade e propusemos o trabalho em grupo com as famílias, no qual foram abordados temas relacionados à educação dos filhos, às relações familiares e comunitárias, temas esses elencados pelo grupo.

Nos encontros, as discussões estiveram sempre relacionadas ao cotidiano das respectivas famílias, buscando proporcionar a reflexão sobre as diferenças individuais, a importância do papel enquanto cuidadores e consequentemente de seus comportamentos, que poderiam resultar em violências. No segundo encontro, durante a abordagem sobre as diferenças individuais, uma das participantes colocou que "[...] uns filhos são feitos com mais carinho e outros com violência" (Vitória). Essa opinião provocou impacto no grupo, uma vez que outras participantes citavam sobre as características físicas. Entretanto, possibilitou discussões intensas a respeito das consequências de tal violência.

Ao longo dos encontros, discutimos também sobre a educação na perspectiva do grupo, questões relacionadas à afetividade e à agressividade, fazendo um paralelo com as consequências que podem implicar no desenvolvimento das suas crianças e adolescentes. 
Durante os encontros, as participantes constantemente traziam suas vivências e as comparavam com os dias atuais, principalmente sobre as situações referentes à forma de educar de seus pais. Esses usavam da agressão física, verbal e de castigos para corrigir os seus filhos. Tais colocações, quando comparadas com a atualidade, eram trazidas de forma positiva, pois afirmavam que, na época, os filhos obedeciam aos pais e eles os tratavam com respeito, o que não ocorre hoje.

Ao discutirmos sobre as situações vivenciadas na infância, as entrevistadas queixaram-se da falta de afetividade e relataram alguns momentos em que foram deixadas marcas negativas por serem punidas e/ou agredidas. Contudo, quando instigadas a refletirem sobre a educação de seus filhos e/ou netos, usaram da mesma forma corretiva que de seus pais, o que pode ser observado no seguinte discurso: “[...] quando meu neto faz arte eu coloco de castigo" (Delma).

Observou-se a dificuldade das participantes em lidar com sentimentos e, principalmente, em expressar sentimentos positivos para seus filhos. Assim, discutimos especificamente sobre o abraço, buscando entender o significado e os motivos de terem aqueles significados para elas, de modo a estabelecer um paralelo no que esse ato implicaria a relação para com seus filhos.

Ao tratarmos sobre o educar, as primeiras concepções e/ou formas apresentadas por elas foram: corrigir algo errado; dar palmadas, falar bravo; usar castigo, gritar; ensinar coisas boas; conversar; aconselhar entre outras. Embora tenham surgido expressões positivas, pelas descrições das situações diárias, o uso de coerção e das agressões, sejam elas físicas, psicológicas e/ou verbais, ainda predominavam no discurso dessas mulheres.

Uma das participantes relatou que por morar e conviver num lugar onde as pessoas usam palavrões diariamente se torna banal o seu uso. "Quando eu cheguei aqui no bairro, doía os meus ouvidos de tantos palavrões e xingamentos, hoje até eu passei a usar e nem machuca mais os ouvidos" (Ângela). Essa foi uma situação de violência apresentada, a qual condiz com uma das definições encontradas por Yves Michaud (2001, p. 7), ao recorrer aos dicionários franceses que referem a "uma disposição natural para a expressão brutal dos sentimentos".

Esta realidade das crianças e adolescentes dessa comunidade se assemelha a dos jovens de Curitiba que participaram da pesquisa de Sallas et al. (2008), pois foi constatado 
o quanto o universo familiar desses é permeado de "pequenas" e "grandes" violências no seu dia a dia, o que acaba banalizando os castigos físicos, maus-tratos, agressões verbais ou físicas.

Essa banalização é evidenciada nos discursos seguintes, citados durante a entrevista grupal, quando as participantes referiam-se à violência:

[...] é do tipo que a gente não tem solução. [...] a gente sente prejudicado, mas já está até acostumado, já acostumou com isso daí, porque do que a gente está vendo hoje, assistindo na televisão, nós aqui estamos sossegados. (Delma)

[...] quando o filho é pequeno a obrigação da mãe é cuidar, agora com 15, 16 anos, corre atrás de bola, fala palavrão, você vai falar, xinga, maltrata a gente, agora é maior que a gente, tem que aguentar tudo isso. (Vitória)

No primeiro discurso, observa-se o conhecimento de que ocorre a violência no contexto familiar e comunitário, que existe um sofrimento causado por ela. Entretanto, ao comparar com o contexto externo, que são noticiados pela mídia, o que se vivencia ali torna-se pequeno, por isso deve-se acostumar com essa violência. Já no segundo discurso, percebe-se que a violência dos filhos maiores se torna algo que ela, enquanto cuidadora, deve suportar, uma vez que eles são maiores e não tem como enfrentá-los. Ainda nesse discurso, percebe-se que quando os filhos eram pequenos, em seu cuidar, esta mãe utilizava-se da autoridade por ser maior e mais forte que os filhos.

Essa última situação foi ao encontro com a afirmação de Viviane Guerra (1998, p. 31), quando ela abordou sobre a violência doméstica contra crianças e adolescentes. Segundo a autora, essa violência concebe o abuso do poder do mais forte contra o mais fraco e que ela traz danos físicos, sexuais e/ou psicológicos à vitima e que, de um lado, implica uma violação de poder de proteção do adulto, e, de outro, é uma negação do direito que crianças e adolescentes têm de ser tratados como pessoas em condição peculiar de desenvolvimento.

Essa concepção de violência nos remete à ideia do poder de subjugar o outro, de anular, de usar a força contra alguém, que ao passar da medida se torna um incômodo ao outro. 
Nos relatos das situações diárias, durante os encontros foi evidenciada a banalização da violência. Contudo, durante a entrevista grupal, quando solicitado para as entrevistadas definirem violência, a maioria delas teve dificuldade em conceituar a violência ou até mesmo descrever situações de violência. Vejamos algumas das definições:

[...] a violência, ela tem de vários tipos, de vários jeitos, ela tem a violência de dentro de casa, às vezes tem na vila, na rua, então pra mim tem vários tipos de violência [...] (Delma).

[...] nós estamos vivendo na violência, nós temos que saber lidar com o que esta acontecendo, nós temos que saber levar, só que estamos vivendo na violência e é tudo geral, geral (Mariana).

Observa-se uma dificuldade em se dar um significado para a palavra violência, mas tem-se o conhecimento de que convivemos diariamente com ela, e que é algo que está ocorrendo em todos os lugares, que temos que saber viver com ela, indo ao encontro do que dizem Minayo e Souza (1999) quando verificam nas pesquisas o quanto é difícil conceituar a violência, pois ela pode ser uma forma própria de relação pessoal, política, social e cultural; e ainda pode ser uma resultante das interações sociais ou até um componente cultural naturalizado.

Duas das participantes abordaram a violência de forma mais ampla, pontuando sobre as violências sofridas diante da precariedade da política pública básica e das ações dos agentes institucionais.

[...] é violência, você chegar doente no posto médico e você ficar doente lá e esperar a boa vontade do médico para te chamar pra te atender, é tudo violência, é falta de respeito com a gente, é violência. Tem uns companheiros que até batem na mulher dentro da casa, tudo isso, é violência, a falta de respeito, a falta de emprego, pessoas não respeitar a família dos outros, é tudo violência (Mariana).

É violência sim quando o professor desacata o aluno na sala, fala em bater no aluno [...] Aqui nesta escola eles humilham, ainda mais o meu filho que já foi preso, eles humilham, [...] e na outra escola foi chamado de marginal ai eu fui dar queixa, reclamar lá no Núcleo Estadual de Educação, para que serve aquele núcleo na Maringá. Para nada (Desirée).

Esses fatos descritos são decorrentes do encolhimento da função do Estado de garantir e assegurar as atenções básicas de proteção, desenvolvimento e inclusão social. Situações como essas são consequências da precariedade em que se encontram 
determinadas áreas da política pública, como a educação e a saúde. Esse cenário vem ao encontro da afirmação de Ana Luisa Sallas et al. (2008), que descreve que é na inexistência e/ou na precariedade das ações da esfera pública que a violência emerge, atingindo particularmente os mais pobres.

Isso ficou evidente no discurso da mesma entrevistada que, ao descrever a sua ida ao Núcleo de Educação para defender os direitos do seu filho e exercer a função protetiva, salientou:

No Núcleo eu fui falar [...] e não adiantou nada. Eles não respeitam o pai, eles acham que são melhores porque estudou e são melhores, mas, eles são mais sem educação que os alunos. [...] é dinheiro faz a diferença, [...] agora você por ser pobre é humilhada (Desirée).

Maria do Carmo Carvalho (2006) afirma que é neste cenário de desigualdade social e de exclusão que a família ganha importância na política social, sem receber dos poderes públicos as atenções necessárias para exercer sua função protetiva.

A família tem sido chamada a preencher essa lacuna, como uma das alternativas para enfrentamento das mazelas da questão social. Muitas vezes, na nossa prática, deparamonos com situações difíceis que, pela ausência de políticas sociais, as quais deveriam ser implementadas pela esfera pública, restou-nos buscar somente a suporte familiar para responder às questões relacionadas, principalmente, às crianças e aos adolescentes.

Assim, para que a família possa responder à sua função e ser um lugar de proteção de forma a promover a integração social e o desenvolvimento pessoal de seus membros, é necessário conhecer a família da qual se fala, compreender sua inserção social e o papel destinado a ela nas políticas sociais.

Heloisa Szymanski (1992) pontua que, ao trabalhar com famílias, alguns cuidados são necessários, dentre eles, talvez, o mais relevante seja compreender a problemática apresentada e evitar julgamentos baseados em preconceitos científicos, moralistas ou pessoais, ou seja, respeitar aquelas pessoas com as quais trabalhamos, na sua individualidade, nas suas crenças e valores. A autora enfatiza a importância de conhecer os valores, mitos e crenças que se criaram a respeito do que é a família.

No trabalho desenvolvido pela equipe do Programa Atitude no Quati, como descrevemos nos parágrafos anteriores, buscou-se conhecer a dinâmica familiar e da 
comunidade, as relações estabelecidas e entender a família sempre a partir de sua perspectiva e dentro de seu contexto, trabalhando a partir dos conhecimentos da comunidade.

Durante as intervenções da equipe, uma das mães relatou uma mudança na rotina familiar após três encontros:

Hoje faço as tarefas e refeições juntamente com os meus filhos, diferente de antes, que não tinha uma rotina e nem horário para comer. A diferença é que hoje as crianças esperam por este momento, cobram o almoço (Ângela).

Após este discurso, foi pontuado o quanto esta mudança do comportamento da mãe tornou o momento prazeroso, e, que ao repetir essa atitude, a probabilidade de tornar o estudar um momento agradável e a criança passar a gostar seja maior. Outra mãe relatou que percebeu que a filha está menos agressiva, gritando menos depois que mudou o seu comportamento com ela, o que tornou a relação menos estressante e mais agradável. Enfatizamos, naquele momento, a importância da mudança do nosso comportamento enquanto cuidador, por termos maior habilidade de entendimento e controle desses.

$\mathrm{Na}$ entrevista com o grupo, questionamos sobre o trabalho desenvolvido na comunidade e, de forma específica, sobre o acompanhamento à família, em grupo, em visitas e atendimentos domiciliares. De uma forma geral, relataram que os encontros foram descontraídos, possibilitando momentos de reflexão, que contribuíram para mudanças de atitude e que propiciaram melhoras nas relações familiares, como os discursos anteriormente descritos e os que seguem abaixo:

A gente fala dentro de casa, eu tiro pelo meu molequinho, que eu crio, se ele está lá dentro de casa e faz alguma coisa errada e eu brigo com ele, ele vai pra rua, e eu não o quero na rua, [...] então eu já fiz errado, então, eu tenho que corrigir ele ali dentro, falar não filho faz as coisas ai, você tem que ficar aqui dentro da casa, não quero que você fique na rua, porque eu não gosto [...] (Delma).

Você vai falar e as pessoas não obedecem. Aí você sai na rua e as pessoas falam coisas que é pior que uma tapa na cara. Aí você vai descontar em quem? Nas crianças, porque você esta bufando de raiva dai gera essa violência (Desirée). 
O acompanhamento às famílias evidenciou que, ao longo do tempo, as pessoas desenvolvem suas representações sociais, interpretações e avaliações que foram se organizando, e, dependendo das consequências geradas nessas relações estabelecidas, elas vão escolhendo maneiras específicas de viver uma com as outras, que vão se cristalizando no seu dia a dia.

Essa realidade é condizente com a afirmação de Heloisa Szymanski (1992, p. 25), quando verificou que "modos de relações interpessoais são aprendidos e podem ser modificados quando se propõe a mudar as interpretações das experiências". A autora constata que o primeiro passo para mudar uma interpretação é aprender a olhá-la por outro ângulo.

Acreditamos que o trabalho em grupo proporcionou o falar, o ouvir, o compartilhar, o discutir, o refletir e o olhar para os aspectos positivos de seus familiares, sendo esses fundamentais para iniciar a mudança no contexto familiar, e isso foi possível observar nos discursos anteriormente citados.

Tivemos ainda a oportunidade de realizar um feedback dos técnicos da Unidade Básica de Saúde (UBS), em outubro de 2010, quanto às percepções em relação a comunidade Quati:

Houve realmente uma melhora o pessoal que é acompanhado pelo Programa Atitude, em termos de autoestima, na área da saúde mesmo eles estão procurando se cuidar mais e tem um comportamento diferente. Tem vários anos que a gente acompanha o pessoal, mas depois que $o$ Atitude entrou na comunidade do Quati, a gente observa que houve sim uma melhora considerável, mesmo no comportamento das pessoas dentro da comunidade, em relação a tudo. Até mesmo em tratamento deles, um com os outros, então é importante que dê continuidade ao Projeto; que é bom, e a comunidade necessita de pessoas que estejam na comunidade fazendo coisas que sejam em benefício a ela. Até aqueles meninos que são usuários de drogas, que a gente sabe, conhece não estavam com o mesmo comportamento de antes, então isso é reflexo do trabalho [...] estão respeitando mais a nossa presença também (SILVA, 2010).

O Programa Atitude veio a acrescentar somente benefícios para a comunidade Quati, principalmente na relação da população com a Unidade Básica de Saúde [...] estão mais acessíveis, a integração conosco, melhorou o comportamento deles, a vida deles, porque às vezes eles nem chegavam, eles evitavam, agora eles nos procuram, há um diálogo, a gente está conseguindo ter um diálogo com eles agora, ele procuram pela 
saúde, mas também há uma integração social. Houve melhora em todos esses aspectos (STRIQUER, 2010).

Pelos relatos apresentados, percebeu-se que houve uma mudança positiva nessa comunidade, o que também refletiu na forma de agir dos prestadores de serviços da saúde, e que isso talvez não tenha sido observado por eles. Acreditamos que as mudanças citadas são contribuições de um trabalho sistemático, planejado e pensado especificamente para e com essa comunidade, considerando suas especificidades.

Ainda em relação às mudanças observadas, a técnica da Unidade Básica de Saúde (UBS) exemplificou uma situação na qual fica claro que muitas vezes faltam informações à comunidade sobre o trabalho desenvolvido pelo serviço e até mesmo a falta de conhecimento em relação aos seus direitos:

Uma gestante como ela mudou o seu comportamento em relação ao serviço de saúde depois que o Programa Atitude entrou na comunidade e começou a trabalhar no bairro Quati. Ela teve uma mudança de comportamento muito grande, inclusive houve um episódio em que a agente comunitária foi entregar uma guia e ela queria agredir a menina [...] Então, para você ver como era o comportamento dela, de agressividade em relação à saúde, e hoje em dia não, ela ligou na Unidade e a gente pediu para ela subir passar pelo médico, abrir o pré-natal e ela veio numa boa. Sabe, então o comportamento dela mudou consideravelmente. Isso a gente deve ao trabalho do Programa Atitude que conseguiu colocar lá dentro do Quanti o que realmente é o trabalho na área da saúde, o direito que eles têm à saúde e como eles podem ter bom relacionamento com os profissionais da área também (STRIQUER, 2010).

Maria do Carmo Carvalho (2006) enfatiza que, para o potencial protetor e relacional apontado pelas famílias, só é passível de otimização se ela própria receber atenções básicas. Entende-se que esta questão também está implícita no Estatuto da Criança e do Adolescente (BRASIL, 1990), quando em seu artigo $4^{\circ}$ corresponsabiliza a comunidade, a sociedade em geral e o poder público na efetivação dos direitos da criança e do adolescente.

No que diz respeito às atenções básicas, entendemos que devem ser de responsabilidade de todas as políticas públicas: habitação, educação, saúde, assistência social, esporte, cultura entre outras. Dessa forma, nesses dois anos de trabalho, buscamos aproximações com a rede de serviços para fortalecê-la de forma a garantir os direitos das 
famílias e, principalmente, das crianças e adolescentes. Isso pode ser identificado no discurso abaixo:

Há uma integração com os serviços, a gente procura sempre ter reuniões periodicamente, não somente nossa, mas com até serviços religiosos, educação, entidades, todos os serviços para que tenha uma integração para melhor atender a população do Quati [...] e quem fez esse elo, quem iniciou isso foi o Atitude, eles que juntaram partes e conseguimos fazer um bloco para poder assistir melhor essa população. Foi através do Programa Atitude que conseguimos isso, foram eles que começaram (STRIQUER, 2010).

Foi possível vivenciar e constatar a complexidade do trabalho articulado em rede de serviços, mas que, quando isso ocorre, o trabalho se torna menos pesado, sendo possível melhorar o fluxo e juntos buscar outras estratégias de intervenção, maximizando a possibilidade de colher resultados positivos. A partir dessas citações dos agentes envolvidos, assim como das famílias dos participantes, verifica-se que foi possível modificar as interpretações das experiências ouvindo profissionais de outros serviços.

Pudemos identificar, ainda, que mudanças ocorreram. Temos que a experiência do Atitude pode ter sido um primeiro passo para iniciar a superação da violência, no entanto, é primordial a continuidade de um trabalho próximo e sistemático que dê suporte a essa comunidade e não se feche em si mesmo, deixando novamente essas famílias em desamparo, atendendo, sobretudo, às expectativas das participantes, conforme o discurso abaixo:

[...] eu acho que ajudou bastante, porque mudou bastante pra melhor, porque teve muita criança, muito menor por ai que estavam desamparados e o Programa Atitude conseguiu lugar para menor $e$ muitas pessoas também que queriam trabalhar. Eu conheço pessoas que entrou no trabalho desta comunidade. Eu acho que tinha ser mais ainda, [...] ai sim consegue abaixar ainda mais a violência (Delma).

Por esse discurso, percebe-se que o Programa Atitude conseguiu amparar algumas das crianças e dos adolescentes da comunidade, mas que é necessária a continuidade do trabalho para que diminua a violência na comunidade.

\section{Considerações Finais}


No início da nossa prática no Programa, presenciamos inúmeras situações que, ao nosso olhar, entendíamos como violentas, e era inconcebível que estivessem ocorrendo, principalmente porque envolvia crianças e adolescentes. Assim, a primeira reação seria tentar impedir, a qualquer custo, tal fato, mas não tínhamos este poder, uma vez que estávamos dentro de uma comunidade com sua dinâmica e cultura específica. Ainda era preciso conhecer a família para a qual dirigiríamos as nossas propostas e práticas e compreender a sua inserção social.

A convivência semanal no decorrer desses dois anos de trabalho na comunidade Quati nos permitiu identificar e entender que muitas daquelas interações eram as relações estabelecidas por várias gerações familiares. Eram modos de agir com os outros, os quais foram aprendidos pelas pessoas da comunidade, muitas vezes, como alternativas e soluções para os problemas de interação no grupo familiar e com os serviços públicos.

Entretanto, durante as intervenções do grupo com as famílias, verificou-se que as participantes identificam a violência presente nas sociedades afora, na própria comunidade e até mesmo em sua própria casa, parecendo, contudo, ter dificuldade em reconhecerem que, muitas vezes, elas adotavam a violência para educar seus filhos, assim como os seus pais e avós faziam, sem refletir sobre isso. Observou-se a banalização da violência no cotidiano das pessoas nessa realidade, pois a violência, por vezes, é algo que está incutido em nossa sociedade, nos valores sociais, históricos e culturais.

Vimos que conceituar a violência é algo difícil em decorrência da amplitude dos significados e de sua complexidade. Entretanto, identificou-se na opinião das famílias a compreensão de que existe a violência praticada pelas instituições, e que em muitas situações ela está diretamente associada à violência social.

No que diz respeito à esfera pública, este estudo possibilitou analisar e refletir o quanto é necessária a implementação e/ou a sua melhoria, no que concerne às políticas públicas de atenção básica de qualidade à população, que possibilite um acompanhamento sistemático às famílias.

O trabalho realizado em grupo, com essas famílias, estreitou mais ainda as relações entre elas, possibilitando discussões sobre questões relacionadas à educação de filhos e às relações familiares, propiciando a reflexão das interações estabelecidas na dinâmica familiar e comunitária. Constatamos que tais reflexões trouxeram mudanças de 
comportamento nos contextos familiar e comunitário e que isso refletiu diretamente nas relações interpessoais.

Dessa forma, avaliamos que houve uma redução da violência interpessoal e verificamos o quanto a família pode contribuir nesse processo. Entretanto, ainda existe a necessidade da continuidade de um trabalho de forma mais sistemática para que diminuam os riscos sociais, aos quais, esta comunidade está exposta.

Ao falarmos sobre a continuidade do trabalho, surgem alguns questionamentos. Caso houvesse a continuidade do trabalho com essas famílias, sem previsão de término, teria alcançado tais avanços? Por outro lado, como ficará essa comunidade na ausência de um serviço que estava semanalmente presente? São questões que ficarão sem respostas nesse momento, pois não temos nenhum serviço que esteja presente na comunidade de forma contínua nesse formato. Talvez devesse a esfera pública implementar alguns serviços nesse formato por mais tempo para uma avaliação.

Vale pontuar aqui, também, o quanto o saber acumulado do trabalho com famílias é válido na leitura e na compreensão da problemática exposta, bem como a visão que podemos ter das possibilidades de estratégias de intervenção. No entanto, para o trabalho com as famílias, é imprescindível conhecer seus modos de agir e de pensar, criar condições que favoreçam e propiciem o diálogo e a participação para que seja possível a proposição de mudanças.

\section{Referências}

BRASIL. Leis, Decretos. Estatuto da Criança e do Adolescente - ECA. N. 8.069, 13 de julho de 1990. Brasília, 1990.

CARVALHO, M. do C. B. de. O lugar da Família na política social. In: . (Org.). $A$ Família Contemporânea em Debate. 7. ed. São Paulo: Cortez, 2006. p. 15-22.

FEFFERMANN, M. Vidas Arriscadas: O Cotidiano dos Jovens Trabalhadores do Tráfico. Petrópolis, RJ: Vozes, 2006.

GUERRA, V. N. A. Violência de pais contra filhos: a tragédia revisitada. São Paulo: Cortez, 1998.

KURIKI, L. M. K. et al. Relatório sobre as primeiras visitas realizadas a comunidade e a rede de serviços que atendem o bairro Quati. Londrina, 2009.

MICHAUD, Y. A violência. São Paulo: Ática, 2001. 
MINAYO, M. C. de S. (Org.). Pesquisa social: Teoria, método e criatividade. 22. ed. Petrópolis, RJ: Vozes, 2003.

.; SOUZA, E. R. de. É possível prevenir a violência? Reflexões a partir do campo da saúde pública. Ciência \& Saúde Coletiva. Rio de Janeiro, v.4, n.1, p.7-23, 1999.

ONESTI, L. A. Psicologia e Pobreza. Sensibilidade e Compromisso. In: ZAMBERLAN, M. A. T. Psicologia e Prevenção: modelos de intervenção na infância e na adolescência. Londrina: EDUEL, 2003. Cap. 1. p. 1-10.

PARANÁ. Secretaria de Estado da Criança e da Juventude. Orientações para a atuação dos profissionais do Programa Atitude. Curitiba, 2009.

SALLAS, A. L. F. et al. Os Jovens de Curitiba: Esperanças e Desencantos, Juventude, Violência e Cidadania. 2. ed. Curitiba: Editora da UFPR, 2008.

SCHELB, G. Z. Violência e Criminalidade Infanto-Juvenil: intervenções e Encaminhamentos. 2. ed. Brasília: Ed do autor, 2005.

SILVA, L. G. II Fórum dos Trabalhadores da Infância e Adolescência do Município de Londrina. Londrina, 2010. Entrevista concedida a Carlos Alberto Xavier e Edilaine Baccarin.

STRIQUER, M. A. Il Fórum dos Trabalhadores da Infância e Adolescência do Município de Londrina. Londrina, 2010. Entrevista concedida a Carlos Alberto Xavier e Edilaine Baccarin.

SZYMANSKI, H. Trabalhando com Famílias. Cadernos de ação $n^{\circ}$ 1. Centro Brasileiro para Infância e Adolescência (CBIA/SP). Instituto de Estudos Especiais (IEE)-PUC/SP. São Paulo: Forja gráfica e Editora Ltda., março, 1992.

Teorias e "Teorias" de Famílias. In: CARVALHO, M. do C. B. (Org.). A Família Contemporânea em Debate. 7. ed. São Paulo: Cortez, 2006. p. 23-28.

ZAMBERLAN, M. A. T.; FREITAS, M. G. de. Intervenção Familiar para Crianças em Situação de Risco. In: ZAMBERLAN, M. A. T. Psicologia e Prevenção: modelos de intervenção na infância e na adolescência. Londrina: EDUEL, 2003. Cap. 2. p. 11-28.

Recebido em: 13/09/2012

Aprovado em: 30/11/2012 